\title{
A identidade do indivíduo e sua construção nas relações sociais: pressupostos teóricos
}

\author{
The identity of the person and their construction in \\ social relations: theoretical assumptions
}

\author{
Jamile Santinello
}

Doutoranda em Comunicação pela Escola de Comunicação da Universidade Federal do Rio de Janeiro (ECO-UFRJ - 2010-2014) e professora da Universidade Estadual do Centro-Oeste- (Unicentro), com experiência nas áreas de Educação, Comunicação e Informática, e-mail: jamile@unicentro.br

\section{Resumo}

Este artigo objetiva descrever, de maneira sucinta, os pressupostos teóricos da construção da Identidade, tendo em vista o processo identitário do indivíduo, refletido por teóricos e seus referenciais/conceituais/ descrições. Além disso, visa a verificar como ocorreu e ocorre a constituição social da Identidade e suas implicações sociopolíticas mediante aportes teóricos. Este estudo tem a pretensão de identificar os intelectuais que trabalham com o tema e suas considerações perante a sociedade, cada um em sua época, ressaltando a importância dessas discussões teóricas para que possa analisar a realidade atual, isto é, do século XXI. A metodologia utilizada neste trabalho é a descritiva e bibliográfica, tendo em vista análises teóricas das obras referidas.

Palavras-chave: Construção da identidade. Processo identitário. Pressupostos teóricos.

\section{Abstract}

This article aims to describe, in an objective manner, the theoretical assumptions of identity construction, in view of the identity process of the individual, reflected in their theoretical frameworks/conceptual/ descriptions. Besides it checks how the social constitution of identity occurred and is occurring and their socio-political implications, through theoretical studies. This study proposes to identify the scholars who work with the theme, and their remarks in face of society, each in his time, and must emphasize the importance of these theoretical discussions in order to analyze the current reality in the twenty-first century. The methodology used is descriptive literature in view of theoretical analysis of the works mentioned.

Keywords: Identity construction. Identity process. The theoretical assumptions. 
Não vivemos o fim da história, nem mesmo o princípio do fim. Estamos no limiar de outra grande transformação: as forças globais descontroladas, e seus efeitos cegos e dolorosos, devem ser postas sob o controle popular democrático e forçadas a respeitar e observar os princípios éticos da coabitação humana e da justiça social (BAUMAN, 2005, p. 95).

\section{Introdução}

Este artigo tem como objetivo refletir sobre as perspectivas do processo da Identidade mencionada por alguns teóricos e seus referenciais/ conceituais/descrições, bem como sua constituição social e suas implicações sociopolíticas identitárias do sujeito. Isso será feito mediante aportes teóricos, tendo em vista a necessidade de referenciar as questões vinculadas ao indivíduo como ser social e inserido em um contexto sócio-político-econômico.

A sociedade, em se tratando de sua constituição, foi e continua sendo permeada por contrastes, paradoxos, paradigmas estabelecidos para a legitimação de poder, bem como a hegemonia e a ideologia na relação entre as classes dominantes e as dominadas, tendo em vista todas as formas de identificação e racionalização da consciência dos indivíduos. As relações de poder sempre estiveram presentes na construção e na constituição da sociedade, sendo que as necessidades de cada indivíduo dependem da representatividade em que ele éinserido, tendo como suporte os valores sociais e subjetivos perante o contexto e a inserção no mundo.

As perspectivas e contribuições deste estudo propõem, inicialmente, reflexões sobre os processos comunicacionais do estabelecimento e a construção da Identidade em relação com a realidade social. Posteriormente, serão postas argumentações sobre o paradoxo da sociedade atual relatado por alguns pesquisadores na área.

A complexidade e a autenticidade deste estudo permitem que haja pesquisas sobre a Identidade do indivíduo e sua constituição, além da mediação comunicacional efetivada pelas tecnologias e o embasamento teórico para subsidiar as ideias centrais. Isso ocorre porque é necessária uma delimitação do objeto para que não haja ambiguidade de conceitos, de bases teóricas ou até mesmo uma não identificação com a realidade social.
É sabido que grande parte das teorias pesquisadas, em diversas áreas como da Comunicação, da Educação, da Filosofia, da História, entre outras, detem suas perspectivas, peculiaridades, particularidades, problematizações e inconsistências, havendo, assim, divergências e convergências. Nesse sentido, há também a possibilidade de um sistema ser ou não reconhecido pelo outro.

Cada sistema teórico constrói, de diferentes maneiras, o seu objeto de estudos. Cada sistema tem seus princípios, seus problemas e suas questões, o que não significa que haja diálogo entre as teorias, mas é preciso que fique claro o limite, por mais que seja tênue, entre elas para evitar o ecletismo (COUTINHO, 2010).

Assim, por um lado, há os pesquisadores críticos com relação ao uso das tecnologias na sociedade atual, descrevendo a desvalorização do ser humano, a supremacia da máquina em relação ao indivíduo. Por outro lado, há os defensores que enaltecem a máquina como alternativa de evolução sócio-histórica, sendo um dispositivo e/ou ferramenta que auxilia o homem em suas atividades, contribuindo para a progressão da sociedade.

\section{Sociedade e Identidade do indivíduo}

Para Virilio (1999, p. 10), “o que é excessivo é insignificante 'uma ciência sem consciência é apenas a ruína da alma' e uma tecnociência sem consciência de seu fim iminente não passa de um esporte que ignora a si mesmo". Assim, enfatizar $\mathrm{e}$ ir ao extremo dos termos e conceitos, tendo em vista suas peculiaridades, é um tanto intransigente e enfático. Corroborando com as descrições e reflexões de Virilio (1999), colocam-se neste artigo discussões sobre a Identidade e sua construção.

Não há como mensurar ou até mesmo delimitar quais são os espaços de intervenções e as caracterizações das maneiras de como se permeiam e se conceituam "as sociedades", tendo em vista as concepções teóricas de cada autor (mediante análises de seus respectivos sistemas teóricos embasamento ideológico), sendo descritas e identificadas como: Sociedade Capitalista, Sociedade da Informação, Sociedade Pós-Moderna, Sociedade Contemporânea, Sociedade do Conhecimento, e outras descrições. 
Assim, há de se ressaltar, em todas essas questões, que os processos comunicativos estão em torno de todas as nuances caracterizadas pela sociedade, haja vista que a comunicação não é apenas o meio, mas a mediação e a produção da consciência, culminando em produção social identitária. Mas, afinal, o que é Identidade? Como ela se constitui? É constituída por si só ou por meio da sociedade? É construída pelas mediações das tecnologias da comunicação e/ou relações sociais?

A complexidade e a dinamicidade da Identidade é um tanto controverso, tendo em vista os autores que estudam sobre a sociedade e a sua constituição. Assim, há considerações relevantes de Bauman, Hall, Giddens, Castells, entre outros, no que tange ao contexto social, e a construção da Identidade e da sociedade, cada um enfatizando e defendendo suas concepções teóricas, bem como aspectos relativos ao processo comunicacional intrínseco nas áreas históricas, filosóficas, sociais, econômicas, educacionais e outras.

Hall (2006, p. 13) destaca que a Identidade está relacionada com a transformação na "modernidade tardia", especificamente ao processo de mudança identificada como "globalização" e o "impacto sobre a Identidade cultural".

O conceito de Identidade e sua constituição transformam-se temporalmente/espacialmente, bem como uma área muito debatida, graças às análises defendidas por teóricos da área, e também a delimitação, se isso assim pode-se dizer, das ideias permeadas pelo termo e suas conjecturas sociais no envolvimento de processos histórico-filosóficos.

Assim, as mudanças sociais caracterizam-se “à medida em que [sic] as áreas diferentes do globo são postas em interconexão uma com as outras, ondas de transformação social atingem virtualmente toda a superfície da terra" (GIDDENS, 1990 apud HALL, 2006, p. 15). "O trabalho continua a ocupar um lugar central na produção da riqueza, na construção da Identidade dos indivíduos e no delineamento das condutas coletivas" (CATTANI; HOLZMANN, 2006, p. 7).

Nesse sentido, a Identidade do indivíduo é construída pela necessidade de sobrevivência, bem como as intrínsecas variabilidades das relações sociais, e sua delimitação do contexto espaço e tempo em que o sujeito está inserido. A Identidade também se expressa, conforme reflexões de Jacques (2006, p. 155), como uma maneira de cada indivíduo se tornar algo em uma composição de grupo, "etnia, raça, gênero, família ou profissão, em que o igual e o diferente convivem simultaneamente".

Os conflitos e os desafios gerados na sociedade atual (intitulada, por alguns autores, como: midiática, digital, da informação, informacional, do conhecimento, informática, entre outros títulos) perpassam por conflitos individuais e coletivos, contextualizados e historicizados.

As reflexões sobre Identidade são densas, e na "tradição socrático-platônica" ela se reporta à essência, de maneira fixa. Mesmo sofrendo transformações, sempre se estabelece a mesma Identidade (JACQUES, 2006). "A tendência atual é concebê-la como uma síntese lógica e ontológica, em cuja constituição as relações sociais ocupam lugar destacado" (JACQUES, 2006, p. 155).

Esses estabelecimentos das reflexões identitárias reportam-se a alguns conceitos e tendências, em que processualmente destacam-se as relações sociais, as transformações dos processos comunicacionais na sociedade e a maneira como são delimitadas por questões de cunho humanístico ou éticos/morais. Assim, cabe ressaltar que as comunidades, sendo que estas definem as Identidades, são divididas em dois tipos: "comunidades de vida e de destino, cujos membros (segundo a fórmula de Siegfried Kracauer) 'vivem juntos numa ligação absoluta', e outras que são 'fundidas unicamente por ideias ou por uma variedade de princípios", (BAUMAN, 2005, p. 17).

Essas questões são defendidas por Bauman (2005) quando ele ressalta a não solidez e o não pertencer da Identidade pela vida toda, pois as relações são negociáveis e o livre arbítrio (maneira de tomar decisões) também está envolvido nesse processo.

[...] a 'identidade’ só nos é revelada como algo a ser inventado, e não descoberto; como alvo de um esforço, 'um objetivo'; como uma coisa que ainda se precisa construir a partir do zero ou escolher entre alternativas e então lutar por ela e protege-la lutando ainda mais- mesmo que, para que essa luta seja vitoriosa, a verdade sobre a condição precária e eternamente inconclusa da deva ser, e tenda a ser, suprimida e laboriosamente oculta" (BAUMAN, 2005, p. 21-22). 
Não obstante, intrínseco às reflexões estão o aspecto da subjetividade do indivíduo e sua caracterização e relação com o meio. Por um lado, a Identidade é constituída de significados e da experiência dos indivíduos (CASTELLS, 2008); por outro,

de cem ou mais anos atrás o 'problema da Identidade' foi moldado pela vigência de um principio de cuins régio, eius natio, os atuais 'problemas da Identidade se originam, pelo contrário, do abandono daquele principio ou do pouco empenho na sua aplicação e da ineficácia de seu fomento onde isso é tentado (BAUMAN, 2005, p. 30).

Os contrapontos e a epistemologia da conceituação identitária dependem dos fundamentos teóricos de cada intelectual, como mencionado anteriormente. Além de todas as proposições mencionadas, os indivíduos também buscam, constroem e mantêm as referências comuns da mobilidade identitária que se encontram em movimento, mas também se conciliam com as junções das relações grupais em um delimitado espaço temporal (BAUMAN, 2005).

Entretanto, Castells (2008) distingue a construção da Identidade em três formas e origens, tendo em vista que essa construção acontece por meio das relações de poder: a Identidade legitimadora, a Identidade de resistência e a Identidade de projeto.

A Identidade legitimadora é inserida por instituições dominantes da sociedade com o objetivo de disseminar e racionalizar seu poder de dominação em relação aos outros atores sociais. A Identidade de resistência é criada por atores sociais que se encontram em desvantagens e estigmatizados pela lógica de dominação, criando barreiras para a sua sobrevivência com base em princípios diferentes dos que norteiam as instituições sociais. A Identidade de projeto é construída a partir de materiais culturais para redefinir posições na sociedade, transformando, assim, a estrutura social (CASTELLS, 2008).

Cada tipo de processo de construção de identidade leva a um resultado distinto no que tange à constituição da sociedade. A identidade legitimadora dá origem a uma sociedade civil, ou seja, um conjunto de organizações e instituições, bem como uma serie de atores sociais estruturados e organizados. [...]. A identidade destinada à resistência, leva à formação de comunas, ou comunidades [...] dá origem a formas de resistência coletiva diante de uma opressão que, do contrario, não seria suportável. [...] A identidade de projeto, produz sujeitos, [...] sujeitos não são indivíduos, mesmo que considerando que são constituídos a partir de indivíduos. São o ator social coletivo pelo qual indivíduos atingem o significado holístico em sua experiência (CASTELLS, 2008, p. 25-26).

A construção da Identidade está interligada com o contexto (CASTELLS, 2008), tendo em vista que todas as intervenções sociais e as características de cada tipo de Identidade conectam-se ao ser social, sendo ao ator social aplicadas as suas necessidades para com a sociedade.

Mas, a respeito de atores sociais, a Identidade é um

processo de construção de significado com base em um atributo cultural, ou ainda um conjunto de atributos culturais inter-relacionados, $\mathrm{o}(\mathrm{s})$ qual(ais) prevalece $(\mathrm{m})$ sobre outras fontes de significados. Para um determinado indivíduo ou ainda um ator coletivo, pode haver identidades múltiplas (CASTELLS, 2008, p. 22).

Hall (2006) identifica três concepções de Identidade, que são: sujeito do iluminismo; sujeito sociológico; e sujeito pós-moderno. Para o pesquisador, o sujeito do iluminismo tem como centro do eu a Identidade de uma pessoa, dotado de razão, consciência e ação, sendo uma concepção individualista do sujeito e de sua Identidade; o sujeito sociológico era constituído na relação com "pessoas importantes para ele" (HALL, 2006, p. 11), mediando os valores, os sentidos e os símbolos (cultura), isto é, a Identidade é construída entre o eu e a sociedade, e preenche o espaço entre o "interior e o exterior, entre o mundo pessoal e o mundo público" (HALL, 2006, p. 11); e, por fim, o sujeito pós-moderno é aquele que não tem Identidade fixa, essencial ou permanente, sendo que essa "Identidade torna-se celebração móvel, formada e transformada" (HALL, 2006, p. 11-12).

A identidade plenamente unificada, completa, segura e coerente é uma fantasia. Ao invés 
disso, à medida em que os sistemas de significação e representação cultural se multiplicam, somos confrontados por uma multiplicidade desconcertante e cambiante de identidades possível, com cada uma das quais poderíamos nos identificar ao menos temporariamente (HALL, 2006, p. 13).

A Identidade pode serinterpretada e reinterpretada de várias maneiras, seguindo os pressupostos teóricos e reflexões paradoxalmente enfatizadas por cada indivíduo e sua complexidade subjetiva. "A construção de identidade assumiu a forma de uma experimentação infindável. Os experimentos jamais terminam" (BAUMAN, 2005, p. 91).

Silva (2008) distingue o processo de produção da Identidade em dois movimentos, oscilando, por um lado, entre a fixação e a estabilidade e, por outro, entre a subversão e a desestabilidade do contexto. Há de se considerar que o pesquisador Hall defende que as "identidades modernas estão sendo 'descentradas', isto é, deslocadas ou fragmentadas" (HALL, 2006, p. 8). e essas questões estão inseridas em um contexto social dicotômico e paradoxo. Além disso, considera-se que "a identidade somente se torna uma questão quando está em crise, quando algo que se supõe como fixo, coerente e estável é deslocado pela experiência da dúvida e da incerteza" (MERCER, 1990 apud HALL, 2006, p. 9).

O século XVIII foi demarcado pelo "sujeito da razão", e com as formações de classe no capitalismo moderno, o cidadão comprometeu-se com as questões burocráticas e administrativas do Estado moderno, surgindo a concepção do sujeito como ser social (HALL, 2006).

Partindo para outras questões, Hall (2006) delimita cinco "descentramentos" do sujeito cartesiano na "modernidade tardia", sendo que originalmente o sujeitoiluminista, visto como "identidade fixa e estável, foi descentrado, resultando nas identidades abertas, contraditórias, inacabadas, fragmentadas, do sujeito pós-moderno" (HALL, 2006, p. 46). Assim, essas cinco implicações conceituais e intelectuais são: 1) tradições do pensamento marxista, sendo o homem sujeito da própria história, considerando as condições em que vive; 2) a descoberta do inconsciente, segundo Freud, ressaltando que a subjetividade é produto de processos psíquicos inconscientes; 3) concepções linguísticas estruturais defendidas por
Saussure, analisando que a língua é um sistema social e não individual; 4) ideias de Foucault, na delimitação do "poder disciplinar", e "manter as vidas, as atividades, o trabalho, as infelicidades e os prazeres do indivíduo, sob estrito controle e disciplina"; 5) impacto do feminismo na década de 1960, politizando a subjetividade, a Identidade e o processo de identificação do sujeito.

Em questões psicanalíticas, seguindo Freud, a Identidade é formada, temporalmente, por meio de processos inconscientes, e não algo inato, permanecendo sempre incompleta, "em processo", em formação (HALL, 2006). Destaca-se que as análises freudianas e lacanianas são duramente questionadas, pois delimitam a Identidade do sujeito como fixa e estável; conjecturando essas afirmativas, o pensamento psicanalítico busca a "Identidade" e constrói biografias que constituem diferentes partes dos "eus", recapturando o prazer fantasioso da plenitude do sujeito.

O sujeito, como ser social, está inserido em um contexto de relações comunicacionais, que age de várias maneiras, conforme o seu envolvimento ao que está preestabelecido. Ele até mesmo pode flexibilizar suas ações perante os processos das transformações sociais e sua caracterização, e, nesse sentido, há as relações de poder e a subjetividade permeando todo o processo.

Assim, há uma preocupação por parte de Sodré (2005) com as influências que podem ocorrer nos aspectos comunicacionais latino-americanos em consequência de uma absorção cultural norte-americana de estudos culturais centrados na diversidade. O autor também afirma que se faz "necessário inserir a problemática da comunicação no espaço político, em busca de um sentido emancipatória, diante da hegemonia mercadológica da mídia transnacional" (SODRÉ, 2005, p. 17).

A própria evolução tecnológica dos processos de midiatização engendra modos diferentes de relacionamento com as Identidades fantasmáticas ou espectrais. $\mathrm{Na}$ mídia tradicional, o fantasma-o sujeito ficcionalizado-permanece inacessível ao contato real, apesar das 'interações coadjuvantes', como jornais, revistas, correspondências, pesquisas de opinião, criados pela própria indústria do imaginário (SODRÉ, 2002, p. 155). 
Além disso, vivemos além do que prevalecia o pensamento "conceitual, dedutivo e sequencial", sem que ainda consigamos trabalhar com a hipótese da práxis identificada com um espírito temporal marcado pela imagem e sensível (SODRÉ, 2005). Os problemas sociológicos são identificados fundamentalmente no século XXI pela modernidade, em face do desenvolvimento do passado e das formas institucionalizadas do presente (GIDDENS, 2003).

O movimento do pensamento é a reflexão do movimento do real transportado para o cérebro dos homens, e é o que determina o movimento do pensamento; todas as formas de consciência são condicionadas pelo material (MARX apud COUTINHO, 2010). O homem não tem essência; a essência dos homens são as relações sociais. O homem faz sua própria história. Não é a consciência que delimita o ser, é o ser social que delimita a consciência. O homem que conhece também transforma. Para transformar a realidade não basta crítica teórica, mas prática para modificação-ser-transformação consciência da realidade-práxis transformadora. O homem é determinado pela educação, e a educação é histórica. Só o trabalho humano cria valor; o valor não existe por si só (MARX apud COUTINHO, 2010).

Em nosso mundo de 'individualização' em excesso, as identidades são bênçãos ambíguas. Oscilam entre o sonho e o pesadelo, e não há como dizer quando um se transforma no outro. $\mathrm{Na}$ maior parte do tempo, essas duas modalidades líquido-modernas de identidade coabitam, mesmo que localizadas em diferentes níveis de consciência (BAUMAN, 2005, p. 38).

Fazer da 'identidade' uma tarefa e objetivo do trabalho de toda uma vida, em comparação com a atribuição a estados da era pré-moderna, foi um ato de libertação-libertacao da inércia dos costumes tradicionais, das autoridades imutáveis, das rotinas pré-estabelecidas e das verdades inquestionáveis (BAUMAN, 2005, p. 56).

\section{Considerações finais}

Os conflitos internos e externos e as necessidades reais do sujeito passam por várias análises antropológicas, sociológicas, econômicas, sociais e educacionais, tendo em vista as visíveis transformações ocorridas com o passar dos séculos, das décadas, dos milênios e suas repercussões no desenvolvimento das sociedades e das Identidades.

A contradição vislumbrada na sociedade atual faz com que as ações humanas tornem-se conflitantes e até mesmo surjam dúvidas sobre qual caminho a ser seguido. Consequentemente, perde-se a direção das organizações, da construção social e de outras implicações que ocasionam o não desenvolvimento da sociedade.

Portanto, é salutar ressaltar, finalizando as postagens deste texto, as ideias dos pesquisadores quanto à conceituação e às reflexões sobre a Identidade. Assim, Bauman analisa que a construção da Identidade é assumida de maneira experimental infindável; para Hall, a Identidade está relacionada com Modernidade Tardia, isto é, com o processo de mudança social, caracterizado pela globalização e pelo impacto sobre a Identidade cultural; para Jacques, a Identidade expressa o sujeito, o grupo e sua convivência mútua; para Castells, a Identidade é algo construído a partir da sociedade civil e da sociedade em rede, emergindo, assim, da resistência comunal; e para Silva, a Identidade oscila, por um lado, entre a fixação e a estabilidade, e, por outro, entre a subversão e a desestabilidade do contexto.

As reflexões sobre a Identidade variam temporalmente, mas continuam sendo ponto de discussões, haja vista a necessidade de análises sobre a caracterização e a compreensão do Indivíduo como ser social e como agente de sua própria construção. Além disso, necessita-se compreender sua identificação perante a realidade social, suas relações com a sociedade, com o trabalho e com as formas de conexão com o mundo, e a maneira pela qual visualiza suas ações no processo de inter-relação com o espaço.

\section{Referências}

BAUMAN,Z. Identidade. Entrevista a Benedetto Vecchi. Rio de Janeiro: J. Zahar, 2005.

CASTELLS, M. O poder da identidade. 6. ed. São Paulo: Paz e Terra, 2008. Publicado originalmente em 1942.

CATTANI, A. D.; HOLZMANN, L. Dicionário de trabalho e tecnologia. Porto Alegre: Ed. da UFRGS, 2006. 
COUTINHO, E. G. Problemas teóricos da comunicação. Programa de Pós-Graduação da Escola de Comunicação da Universidade Federal do Rio de Janeiro. Guarapuava/PR, 12-17 abril 2010. Notas de aula.

GIDDENS, A. A constituição da sociedade. 2. ed. São Paulo: M. Fontes, 2003.

HALL, S. A Identidade cultural na pós-modernidade. 11. ed. Rio de Janeiro: DP\&A, 2006.

JACQUES, M. da G. C. Identidade e trabalho. In: CATTANI; A. D.; HOLZMANN, L. Dicionário de trabalho e tecnologia. Porto Alegre: Ed. da UFRGS, 2006.

SILVA, T. T. da. A produção social da Identidade e da diferença. In: SILVA, T. T. da (Org.). Identidade e diferença: a perspectiva dos estudos culturais. 8. ed. Petrópolis: Vozes, 2008.

SODRÉ, M. Antropológica do espelho: uma teoria da comunicação linear e em rede. Petropolis: Vozes, 2002.

SODRÉ, M. Logos e o phatos, a razão e a paixão no espaço conceitual da comunicação e das novas tecnologias. In: CAPPARELLI, S.; SODRÉ, M.; SQUIRRA, S. (Org.). A comunicação revisitada. Livro da XIII Compós. Porto Alegre: Sulina, 2005.

VIRILIO, P. A bomba informática. São Paulo: Estação Liberdade, 1999.

Recebido: 10/04/2011

Received: 04/10/2011

Aprovado: 08/08/2011

Approved: 08/08/2011 